\title{
Partial acidulation of phosphate rock for enhanced phosphorus availability in alluvial soils of Bihar, India
}

\author{
Kasturikasen Beura*, Rajeev Padbhushan', Amit Kumar Pradhan ${ }^{\mathbf{1}}$ and Nintu Mandal $^{\mathbf{1}}$ \\ *Department of Soil Science \& Agricultural Chemistry, Bihar Agricultural University, Sabour-813210 (Bihar), \\ INDIA \\ *Corresponding author. E-mail: beura.kasturi88@gmail.com \\ Received: October 30, 2015; Revised received: May 08, 2016; Accepted: July 28, 2016
}

\begin{abstract}
The present study was undertaken to fractionate partially acidulated phosphate rock (PAPR) and evaluate its effect on Phosphorus availability in alluvial soils. For this purpose, low grade phosphate rock was collected from Udaipur, Rajasthan and acidulated at different degrees with sulphuric acid $\left(\mathrm{H}_{2} \mathrm{SO}_{4}\right)(\mathrm{v} / \mathrm{v})$ Results from an incubation study showed that the available fraction of $\mathrm{P}$ [Water soluble (WSP) and Citrate soluble (CSP)] increased with increasing degree of acidulation. The maximum WSP was obtained at $50 \% \mathrm{H}_{2} \mathrm{SO}_{4}(52.30 \%$ of total P) and the maximum CSP was obtained at $80 \% \mathrm{H}_{2} \mathrm{SO}_{4}(49.54 \%$ of total P). $50 \%$ dissolution of rock phosphate was the best treatment and found to be at par with that of $60 \%$ and $80 \%$ but was significantly superior to rest of the treatments. The maximum WSP in the soil samples was obtained after acidulation with $50 \% \mathrm{H}_{2} \mathrm{SO}_{4}$ and the maximum Olsen's $\mathrm{P}$ by the $14^{\text {th }}$ day of incubation. An increasing trend was found at initial stages of incubation (7-14 days) with a notable decrease in the later stages. WSP demonstrated the maximum correlation at $40 \%$ dissolution $\left(r=96^{*}\right.$ for first order reaction, $r=95^{*}$ for second order reaction) while for Olsen's $P$, the maximum correlation was found in initial rock phosphate sample ( $r=88^{\star}$ for first order reaction, $r=94^{*}$ for second order reaction). Kinetics analysis of the obtained rock phosphate demonstrated that the PARP has more influence on phosphorus release pattern as compared to the inorganic P (SSP).
\end{abstract}

Keywords: Alluvial soils, Chemical fractions, Incubation study, Partially acidulated phosphate rock, Phosphorus

\section{INTRODUCTION}

Mineral wealth is finite and non-renewable while it is the major resource for development. The optimal and economic use of this precious resource is of great importance. Local phosphate deposits exist in India with some of them being unexploited and most of them of low-grade (Tarafdar, 2013). Currently, majority of the phosphatic fertilisers are imported and are expensive for most of the resource poor farmers in the country. Phosphorus is the most limiting macronutrient after nitrogen in most of the Indian soils. Low phosphate availability in the soils of India, which is a result of high phosphate fixation (60 to $70 \%$ ) by hydroxides of iron and aluminium and calcium carbonate when water soluble P-fertilizer is applied, leads to poor yield of rice (Ghosal and Chakraborty, 2012).Partially Acidulated Phosphate Rocks (PAPRs) are suitable for direct application and are a possible alternative to more expensive soluble phosphate fertilizers in agricultural fields (Hamadi et al., 2012, IFA, 2013,). But the ability of the PRs to release phosphates in plant available forms depends on their particle size, chemical and mineralogical characteristics as well as the properties of the soil in which they are applied. Previous research has revealed that PAPR is as agronomically effective as superphosphate fertilisers on food crops (Chien et al., 2010). We may save our rock phosphate reserve as well as a huge amount of foreign exchange spent for raw materials to prepare $\mathrm{P}$ fertilisers (Sinirkaya et al., 2014). Soils of Bihar are known to be moderate to low in plant available phosphorus $(\mathrm{P})$ content. Although the use of phosphate rock has been well demonstrated in the management of varied soils, its effect in Inceptisols of Bihar under cereal cropping system for enhanced phosphate availability and P-balance has never been studied. A preliminary incubation study was undertaken in order to determine the effect of partial acidulation of rock phosphate obtained from different sources in enhancing the phosphorus availability in a selected alluvial soil.

\section{MATERIALS AND METHODS}

The study was conducted at Bihar Agricultural University, Sabour during the year 2013.

Source and acidulation of rock phosphate: Low grade rock phosphate was collected from the adjoining areas of Udaipur, Rajasthan. The rock phosphate sample was ground and passed through $0.2 \mathrm{~mm}$ sieve. Fifteen crucibles were taken and 50 gram of ground rock phosphate was placed in each of the crucible. For acidulation of the rock phosphate 20, 40, 50, 60 and 80 percent of $\mathrm{H}_{2} \mathrm{SO}_{4}$ solution was prepared with distilled 
water (v/v). Triplicate crucibles were added with $50 \mathrm{ml}$ of each prepared acid solutions in 1:1 ratios (w/v). The rock phosphate after complete acidulation for $24 \mathrm{hrs}$ was then placed in a muffle furnace for complete drying. It was then ground and passed through a $0.2 \mathrm{~mm}$ sieve.

Fractionation of partially acidulated phosphate rock: Acidulated rock phosphate was analysed for water soluble phosphorus (WSP), citrate soluble phosphorus (CSP) and citrate insoluble phosphorus (CISP) following the methods described by (Page et al, 1982) as depicted in figure 1. WSP content was estimated after washing a known weight $(1 \mathrm{~g})$ of the rock phosphate in distilled water. Sample was placed in funnel fitted with Whatman no. 1 filter paper and leached with distilled water till $250 \mathrm{ml}$ of leachate was obtained. The leachate was placed in a 1 litre capacity volumetric flask and volume was made up with distilled water. Pipette out $5 \mathrm{ml}$ of the aliquot and add $5 \mathrm{ml}$ of Barton's reagent and develop the vanadomolybdophosphoric yellow colour complex in a $50 \mathrm{ml}$ volumetric flask. Make up the volume and measure the absorbance at $470 \mathrm{~nm}$ (Koenig and Johnson, 1942).

Sample preparation: Three bulk surface soil (0-15 $\mathrm{cm})$ samples were collected from cultivated fields of adjoining areas of Bhagalpur district in Bihar. Soil samples were air-dried and ground to pass through 2 mm stainless steel sieve. The physico-chemical characteristics of these soils were determined by standard methods (Page et al, 1982). The surface soil samples were analyzed for texture, pH, EC, (Jackson, 1973), soil texture (Bouyoucos, 1962), Organic carbon (Walkley and Black 1934), available nitrogen (Subbiah and Asija, 1956), available potassium Hanway and Heidel, 1952), water soluble phosphorus and Olsen's phosphorus (Olsen et al, 1954) listed in table 1.

Description of the experiment: An incubation study was initiated with the three collected soils in plastic beakers for 1-35 days with a seven-day interval (i.e. $1^{\text {st }}, 7^{\text {th }}, 14^{\text {th }}, 21^{\text {st }}, 28^{\text {th }}$ and $35^{\text {th }}$ day) at $28^{0} \mathrm{C}$ in a BOD incubator. Acidulated phosphate rock (with 20, 40, 50, 60 and $80 \% \mathrm{H}_{2} \mathrm{SO}_{4}$ ), rock phosphate @ $60 \mathrm{~kg} \mathrm{P} \mathrm{ha}{ }^{-1}$ (based on recommended dose of fertilizer for wheat crop) and Single Super Phosphate were added to $100 \mathrm{~g}$ soil sample (in triplicate). Plastic beakers used in the incubation study were arranged in a Completely Randomised Block design. 5-8 drops of toluene were added to the plastic beakers to check the microbial activity. The plastic beakers were shaken daily for six hours on an orbital shaker (at 150 revolutions per minute).

Post-incubation soil sampling and chemical analysis: After incubation the soil samples from the beaker were collected at the above mentioned interval of seven days. The soil samples were ground and analyzed for WSP and Olsen's P based on standard procedure as explained by (Page et al., 1982) and (Olsen et al., 1954) respectively. $\mathrm{P}_{2} \mathrm{O}_{5} \%$ was estimated spectrophotometrically.

\section{RESULTS AND DISCUSSION}

Important soil properties: The soil under consideration was sandy loam in texture having a neutral $\mathrm{pH}$ of 7.15, EC and CEC of $0.34 \mathrm{dSm}^{-1}$ and $11.19 \mathrm{meq}_{100 \mathrm{~g}^{-1}}$ respectively. The mean value of organic carbon was found to be $0.53 \%$ while the mineralizable $\mathrm{N}$ and available $\mathrm{K}$ were to the tune of $160.2 \mathrm{kgha}^{-1}$ and 221.6 $\mathrm{kgha}^{-1}$ respectively.

PAPR fractionation: The incubation experiment was conducted to study the dissolution of Udaipur Rock Phosphate; Single super phosphate (SSP-16\% $\mathrm{P}_{2} \mathrm{O}_{5}$ ); and $20 \%, 40 \%, 50 \%, 60 \%$ and $80 \%$ partially acidulated rock phosphate in alluvial soil collected from agricultural farm located at Bihar Agricultural University, Sabour. The solubility characteristics of the Phosphatic fertilizers were analysed in the laboratory (Fig. 1). At zero degree acidulation of phosphate rock, both WSP and acid soluble P was initially absent, thus unsuitable for use as fertilizer. The percentage of available $\mathrm{P}_{2} \mathrm{O}_{5}$ in PAPR increased with the increase in the degree of acidulation. $50 \%$ PAPR gave high levels of water soluble $\mathrm{P}_{2} \mathrm{O}_{5}(52.30 \%$ of total $\mathrm{P})$ and cut down the expenses whereas $80 \%$ PAPR exhibited maximum CSP (49.54\% of total P). But the $80 \%$ PAPR became sticky because of the presence of free acids. The high rate of reaction causes the calcium sulphate to precipitate from a strongly supersaturated liquid phase to a fine particle size on the surface of unreacted rock phosphate thereby partially blocking contact between the liquid phase and the unreacted rock particles resulting in poor conversion of apatite to soluble forms. Thus the results show that at high acid concentration (60\% and $80 \%$ PAPR) lower percentage of WSP and acid soluble $\mathrm{P}_{2} \mathrm{O}_{5}$ is found in PAPR.

Post-incubation study: The data on $\mathrm{P}$ solubility revealed that among the various $\mathrm{P}$ sources, the water soluble and acid soluble sources released almost double the amount of $\mathrm{P}$, with control treatment. This can be explained by the fact that in the control treatment, the read-

Table 1. Physico-chemical characterization of experimental soil.

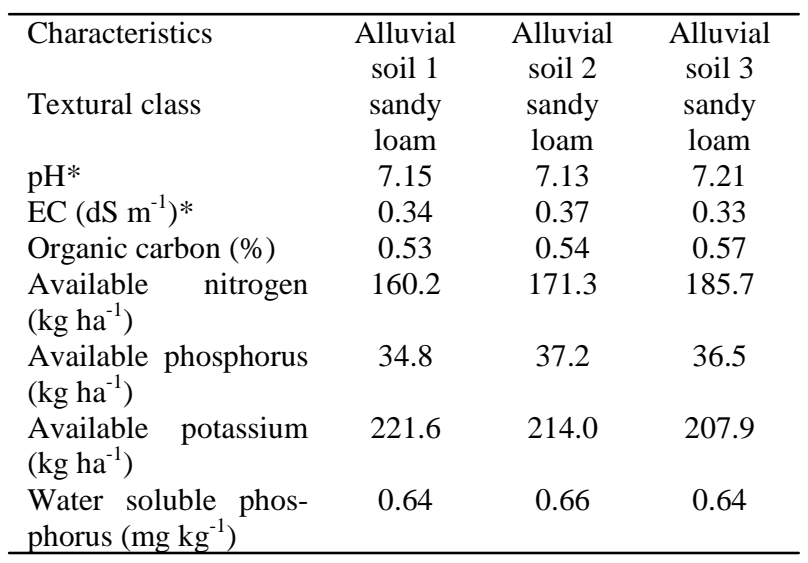

*1:2 soil solution 
Table 2. Mean water soluble phosphorus (WSP) of the three soils during 1-35 days of incubation period for different level of acidulation rock phosphate in $\mathrm{H}_{2} \mathrm{SO}_{4}$.

\begin{tabular}{lcccccc}
\hline $\begin{array}{c}\text { Incubation } \\
\text { period (days) }\end{array}$ & $\mathbf{1}$ & $\mathbf{7}$ & $\mathbf{1 4}$ & $\mathbf{2 1}$ & $\mathbf{2 8}$ & $\mathbf{3 5}$ \\
\multicolumn{1}{c}{ Treatment } & & & & & & \\
\hline Udaipur I & $2.53 \mathrm{~d}$ & $2.31 \mathrm{c}$ & $2.11 \mathrm{~d}$ & $1.29 \mathrm{~d}$ & $1.24 \mathrm{c}$ & $1.17 \mathrm{c}$ \\
$20 \%$ PAPR & $2.51 \mathrm{~d}$ & $2.36 \mathrm{c}$ & $2.17 \mathrm{~d}$ & $1.32 \mathrm{~d}$ & $1.27 \mathrm{c}$ & $1.23 \mathrm{c}$ \\
$40 \%$ PAPR & $2.78 \mathrm{c}$ & $2.46 \mathrm{c}$ & $2.24 \mathrm{~d}$ & $1.56 \mathrm{c}$ & $1.35 \mathrm{~b}$ & $1.26 \mathrm{bc}$ \\
$50 \%$ PAPR & $3.69 \mathrm{a}$ & $3.40 \mathrm{a}$ & $3.47 \mathrm{a}$ & $1.89 \mathrm{a}$ & $1.45 \mathrm{a}$ & $1.36 \mathrm{ab}$ \\
$60 \%$ PAPR & $3.57 \mathrm{ab}$ & $3.34 \mathrm{a}$ & $3.29 \mathrm{ab}$ & $1.84 \mathrm{ab}$ & $1.43 \mathrm{a}$ & $1.35 \mathrm{ab}$ \\
$80 \%$ PAPR & $3.17 \mathrm{~b}$ & $2.92 \mathrm{~b}$ & $3.13 \mathrm{bc}$ & $1.81 \mathrm{~b}$ & $1.41 \mathrm{ab}$ & $1.31 \mathrm{~b}$ \\
SSP & $3.62 \mathrm{a}$ & $3.37 \mathrm{a}$ & $3.08 \mathrm{c}$ & $1.83 \mathrm{ab}$ & $1.45 \mathrm{a}$ & $1.41 \mathrm{a}$ \\
\hline
\end{tabular}

Table 3. Mean Olsen phosphorus of the three soils during 1-35 days of incubation period for different level of acidulation rock phosphate in $\mathrm{H}_{2} \mathrm{SO}_{4}$.

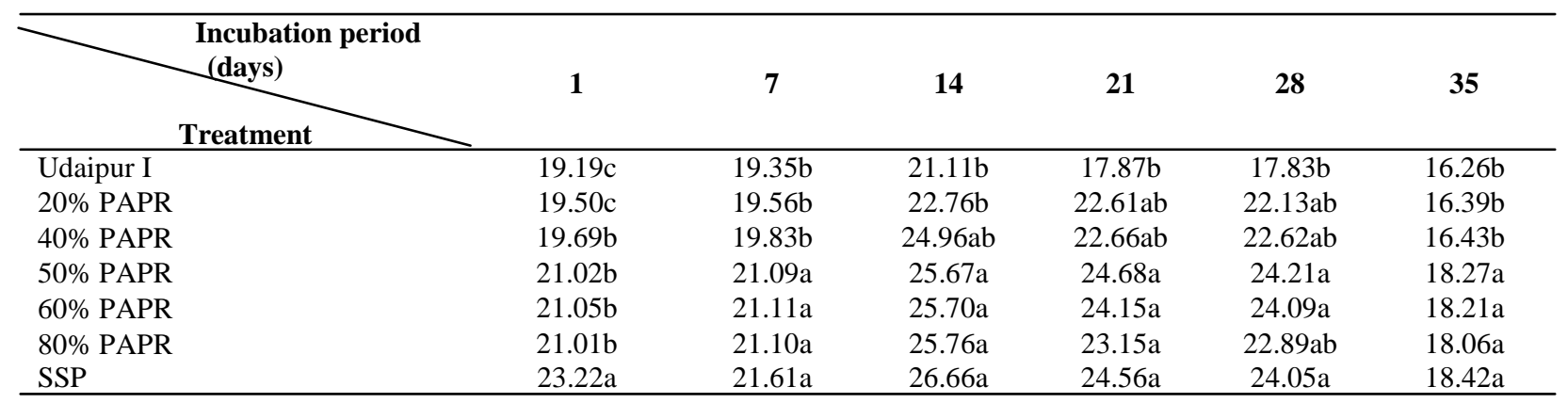

Table 4. Representing first and second order of reaction (Kinetic equation) of PARP and different forms of phosphorus.

\begin{tabular}{|c|c|c|c|c|c|c|}
\hline \multicolumn{7}{|c|}{ First order reaction } \\
\hline \multirow[t]{2}{*}{ Treatment } & \multicolumn{3}{|c|}{ WSP } & \multicolumn{3}{|c|}{ Olsen P } \\
\hline & Intercept & Slope & $\mathbf{R}^{2}$ & Intercept & Slope & $\mathbf{R}^{2}$ \\
\hline Control & -0.456 & -0.001 & 0.60 & 2.750 & -0.000 & 0.63 \\
\hline Udaipur I & 0.967 & -0.025 & 0.90 & 2.969 & -0.004 & 0.88 \\
\hline $20 \%$ PAPR & 0.969 & -0.024 & 0.88 & 3.032 & -0.001 & 0.04 \\
\hline $40 \%$ PAPR & 1.054 & -0.025 & 0.96 & 3.036 & -0.001 & 0.04 \\
\hline $50 \%$ PAPR & 1.430 & -0.033 & 0.89 & 3.103 & -0.000 & 0.01 \\
\hline $60 \%$ PAPR & 1.393 & -0.032 & 0.89 & 3.129 & -0.001 & 0.03 \\
\hline $80 \%$ PAPR & 1.272 & -0.029 & 0.87 & 3.129 & -0.002 & 0.08 \\
\hline SSP & 1.378 & -0.031 & 0.92 & 3.198 & -0.003 & 0.15 \\
\hline \multicolumn{7}{|c|}{ Second order reaction } \\
\hline Control & 1.577 & 0.001 & 0.60 & 0.063 & 0.000 & 0.63 \\
\hline Udaipur I & 0.357 & 0.015 & 0.90 & 0.051 & 0.000 & 0.95 \\
\hline $20 \%$ PAPR & 0.359 & 0.014 & 0.87 & 0.050 & 0.000 & 0.79 \\
\hline $40 \%$ PAPR & 0.324 & 0.013 & 0.95 & 0.049 & 0.000 & 0.69 \\
\hline $50 \%$ PAPR & 0.200 & 0.015 & 0.89 & 0.047 & 0.000 & 0.94 \\
\hline $60 \%$ PAPR & 0.210 & 0.015 & 0.89 & 0.043 & 0.000 & 0.04 \\
\hline $80 \%$ PAPR & 0.245 & 0.014 & 0.88 & 0.043 & 0.000 & 0.09 \\
\hline SSP & 0.219 & 0.014 & 0.91 & 0.040 & 0.000 & 0.17 \\
\hline
\end{tabular}

ily available $\mathrm{P}$ reacts with the $\mathrm{Fe}, \mathrm{Al}$ and $\mathrm{Ca}$ ions in the soil thereby forming iron and aluminium phosphate complex as intermediate products.

It was interesting to note that on the $1^{\text {st }}$ day of incubation, water soluble P released from $50 \%$ PAPR was numerically higher when compared to that of SSP and significantly superior to rest of the treatments (Table 2 ). At incubation stage of the $7^{\text {th }}$ day and thereafter the water soluble $\mathrm{P}$ decreased and the trend was found to be similar for each treatment. This can be ascribed to adsorption of soluble P from soil solution by the re-precipitated poorly crystalline ferrous hydroxides or carbonates formed by soil reduction (Patrick et al., 1985), Ponnamperuma, 1985) and (Tian-ren et al., 1989).

The solubility of P may influence PR dissolution products since the $\mathrm{P}$ released from PRs is effectively removed from solution by iron and aluminium oxides, thus creating a gradient for further dissolution (Lassisa et al.,2015, Smyth and Sanchez, 1982).

It was found that during the $7^{\text {th }}$ and $14^{\text {th }}$ day of incubation, Olsen's P released from 50\% PAPR was at par with that of SSP, $60 \%$ and $80 \%$ PAPR and was signifi- 


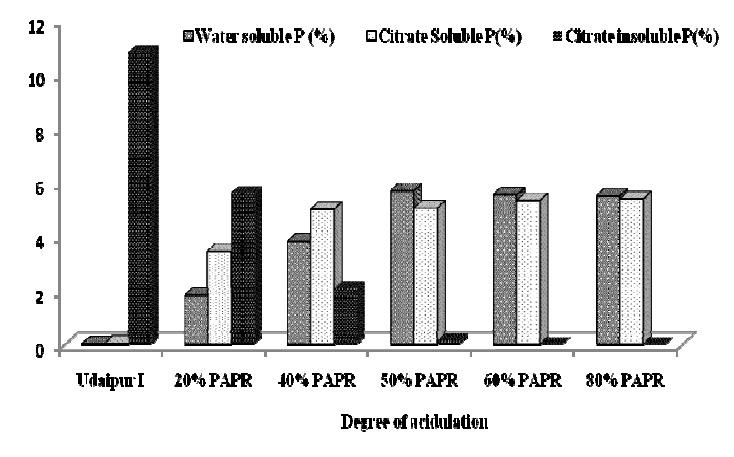

Fig. 1. Fractionation of partially acidulated rock phosphate.

cantly superior to rest of the treatments (Table 3) with a decrease in the later periods (i.e. after 14 days). This is obviously due to the presence of water soluble and acid soluble $\mathrm{P}$ which was released earlier and get fixed in due course of time. A probable explanation for this may be the presence of Al-P and Fe-P in the rock phosphate crystals and in the intermediate products of the soil-PR interaction, from where the alkaline Olsen's extractant may dissolve potentially unavailable $\mathrm{P}$ and thus lead to overestimation of P (Rajan et al., 1996). Increased dissolution of the rock phosphates when added to soils may also be attributed to the neutralization of the $\mathrm{OH}^{-}$ ions, released on hydrolysis of the phosphate ions, due to soil acidity. (Chhonkar, 1994, Mizane, and Rehamnia, 2012)) also reported that $P$ availability to plants was significantly increased in soil.

The trend of P-release by the fertilizers was more pronounced in the treatments, 50\% PAPR and SSP. (Barnes and Kamprath, 1975) and (Singh et al., 1976) also reported an increase in P-availability with the length of incubation period and opined that it may take 4 to 8 weeks for phosphate rocks to reach their maximum solubility. (Chhonkar, 1994) and (Sinclair et al., 1993) explained that this is due to the insoluble characteristic of the phosphate rock where a time lag is experienced for acidulated rock phosphates to reach the maximum effectivity (Chaabouni et al., 2013).

Table 4 represents the first and second order of reaction for the rock phosphate considering the different forms of phosphorus and rock phosphate treated with different levels of sulphuric acid. The intercept, slope and correlation were computed based on the first and second order of reaction. Kinetics analysis indicated that the first and second order of reaction for water soluble form which resulted the best fit. The results showed that water soluble forms were best correlated with different partially acidulated rock phosphate as compared to Olsen's P. For WSP, the maximum correlation was obtained at $40 \%$ PARP $\left(r=96^{*}\right.$ for first order reaction, $\mathrm{r}=95^{*}$ for second order reaction). For Olsen's $\mathrm{P}$, the maximum correlation was obtained in Udaipur initial rock phosphate $\left(r=88^{*}\right.$ for first order reaction, $r=94 *$ for second order reaction). Kinetics analysis of the obtained rock phosphate suggests that PARP has more influence on phosphorus release pattern as compared to the inorganic P (SSP).

The solubility pattern of the phosphatic fertilizers thus resulted the order of solubility of $\mathrm{P}$ or its reactivity to be: $50 \%$ PARP $>$ SSP $>60 \%$ PARP $>80 \%$ PARP $>40 \%$ PARP $>20 \%$ PARP $>$ Udaipur Rock Phosphate for water soluble $\mathrm{P}$, and a order of SSP $>80 \%$ PARP $>60 \%$ PARP $>50 \%$ PARP $>40 \%$ PARP $>20 \%$ PARP $>$ Udaipur Rock Phosphate for Olsen's P. But non significant difference was observed between SSP, 80\% PAPR, 60\% PAPR and $50 \%$ PAPR as far as Olsen's P is concerned.

\section{Conclusion}

Raw URP has very little potential for direct application in the studied soils but when acidulated, its effectiveness as $\mathrm{P}$ fertilizer is enhanced. In this experimental investigation, the effect of partial acidulation of the collected rock phosphate samples on the phosphorus availability was studied. In comparison to SSP, 50\% partially acidulated Udaipur rock phosphate in the soils was reactive enough to provide plant available $\mathrm{P}$ to satisfy the early $\mathrm{P}$ requirement of crops found to be the best among all other treatments because it increases the water soluble $\mathrm{P}_{2} \mathrm{O}_{5}$ recovery substantially. Solubility measurement cannot be used to predict specific yield response but they can serve as a useful means of predicting relative performance of one source over another and this is useful in selection of the most appropriate source. It can thus be concluded that low grade Indian phosphate rocks can be efficiently used as fertilizers in soils upon acidulation.

\section{ACKNOWLEDGEMENTS}

Authors are grateful to Vice-chancellor, Bihar Agricultural University (BAU), Sabour, Bihar, India for providing financial assistance and necessary facilities to carry out this investigation. The authors are also indebted to Directorate of Research, BAU for their support and critical suggestions during the study.

\section{REFERENCES}

Barnes, J.S. and Kamprath, E.J. (1975). Availability of North Carolina rock phosphate applied to soils. North Carolina Agricultural Station Technical Bulletin 229.

Bouyoucos, G.J. (1962.) Hydrometer method improved for making particle size analysis of soils. Agronomy Journl 54: 464.

Chaabouni, A., Chtara, C., Nzihouc, A., and El Feki, H. (2013) Kinetic study of the dissolution of Tunisian natural phosphate or francolite in industrial phosphoric acid. J. Adv. Chem. 6(1).

Chhonkar, P.K. (1994). Mobilisation of soil phosphorus through microbes: Indian experience. Phosphorus research in India, Proceeding of group discussion held at IARI, New Delhi 120-125.

Chien, S.H., Prochnow Luis, I. and Mikkelsen, R. (2010). 
Agronomic Use of Phosphate Rock for Direct Application. Better Crops. 94:21-23.

DAPR, (2013). Direct application of phosphate rock, International Fertilizer Industry Association (IFA) www.fertilizer.org March. 4.

Ghosal, P.K. and Chakraborty, T. (2012). Comparative Solubility Study of Four Phosphatic Fertilizers in Different Solvents and the Effect of Soil. Resources and Environment. 2(4): 175-179.

Hamadi, A.S., Remedhan, S.T. and Ali, H.A. (2012). Phosphate rock treatment with hydrochloric acid for increasing P2O5 content, Eng. And Tech Journal. 30:67-76.

Hanway, J.J. and Heidel, H. (1952). Soil analysis methods as used in Iowa State College Soil Testing Laboratory. Bulletin 57, Iowa State College of Agriculture, Iowa, USA, pp 131.

Jackson, M. (1973). Soil Chemical Analysis, Indian Reprint, Prentice- Hall of India Pvt. Ltd. New Delhi, India.

Koenig, R.A. and Johnson, C.R. (1942). Colorimetric determination of phosphorus in biological materials. Indian Engineering Chemical Analysis.14:155-156.

Lassisa, M., Mizanea, A., Daddab, N., and Rehamnia, R. (2015) Dissolution of Djebel Onk phosphate ore using sulfuric acid, Environmental Nanotechnology, Monitoring \& Management. 4:12-16.

Mizane, A. and Rehamnia, R. (2012) Study of some parameters to obtain the $\mathrm{P}_{2} \mathrm{O}_{5}$ water-soluble from partially acidulated phosphate rocks (PAPRs) by sulfuric acid. Phosphorus Res. Bull. 27: 18-22.

Olsen, S.R., Cole, C.V., Watanable, F.S. and Dean, L.A. (1954). Estimation of available phosphorus on soil by extraction with sodium bicarbonate. U.S.DA.A. Curcular.

Page, A.L., Miller, R.H. and Keeny, D.R. (1982). Methods of Soil Analysis.Part 2.Chemical and microbiological Properties. Second edition. American Society of Agronomy,(Eds.). Inc.And Soil Science Society of America, Inc., Madison, Wiscounsin USA.

Patrick, W. H., Jr. Mikkelsen, D. S. and Wells, B. R. (1985). "Plant nutrient behaviour in flooded soil" In: Fertilizer Use and Technology, 3d ed. Soil Science Society of America, Madison Wisconsin 197-228.

Ponnamperuma, F. N. (1985). Chemical kinetics of wetland rice soils relative to soil fertility" In : Wetland Soils : Characterisation, Classification and Utilisation, Interna- tional Rice Research Institute, Los Banos, Laguna, Philippines 71-89.

Rajan, S.S.S., Watkinson, J.H. and Sinclair, A.G. (1996). Phosphate rocks for direct application to soil. Advances in Agronomy. 57: 77-159,

Rajan, S.S.S.,Gillingham, A.G.O., O'Connar, M.B., Percival, N.A. and Gray, M.G. (1987). "Ground phosphate rocks as fertilizers for pastures" In : The use of reactive phosphate rocks and their derivatives as fertilizers. Ed. by White, R. E. and Currie, L. D. Occassional Report No. 1, Massey University, Palmerston North, New Zealand 78-83.

Sinclair, A.G., Johnstone, P.D., Smith, L.C., O'Connor, M.B. and Nguyen, L. (1993). Agronomy, modeling and economics of reactive phosphate rocks as slow release phosphate fertilizers for grasslands. Fertilizer Research. 36:229-238.

Singh, D., Mannika, N. D. and Srivas, N. C. (1976). Fertilizer value of indigenous rock phosphates compared with single super phosphate : Laboratory incubation studies with farm yard manure, Journal of Indian Society of Soil Science. 24 (1):78-80.

Sinirkaya, M., Ozer, A.K., Gülaboglu, M.S.(2014) Investigation of the solubilities of sulfated and ground phosphate rock after sulfation in $\mathrm{H}_{2} \mathrm{SO}_{4}$ solution. Pamukkale Univ. J. Eng. Sci. 20 (7):253-257.

Smyth, J.J. and Sanchez, P.A. (1982). Phosphate rock dissolution and availability in Cerrado soils as affected by Psorption capacity. Soil Science Society of America Journal. 46:330-345.

Subbiah, B.V. and Asija, G.L. (1956). A rapid procedure for assessment of available nitrogen in soils. Current Science. 31:159-160.

Tarafdar, J.C. (2013.) Phosphorus- A Bright Future Ahead ! Journal of Indian Society of Soil Science. 61: 29-37

Tian-ren, Y., Kirk, G. I. D. and Chaudhury, F. A. (1989). Phosphorus chemistry in relation to water regime, Proceedings of symposium on Phosphorus Requirements for Sustainable Agriculture in Asia and Oceania, 6March, International Rice Research Institute, Los, banos, Laguna Philippines.

Walkley, A. and Black, C.A. (1934). An examination of the Degtjareff method for determining soil organic matter and a proposed modification of the chromic acid titration method. Soil Science. 37:29-38. 